\title{
APRESENTAÇÃO
}

\section{A pesquisa em políticas educacionais e os 10 anos do NuPE/UFPR}

\section{Education policies research and NuPE/UFPR 10th aniversary}

\section{Ângelo Ricardo de Souza}

Este número do Jornal de Políticas Educacionais é muito importante para nós. Ele foi constituído com o intuito de ser um dos canais de comemoração do $10^{\circ}$ aniversário do Núcleo de Políticas Educacionais da Universidade Federal do Paraná- NuPE/UFPR, berço do próprio JPE. Este periódico, de resto, é mais uma das frentes de trabalho desenvolvidas pelo NuPE, que se soma ao conjunto de ações de pesquisa, ensino e extensão que os seus pesquisadores têm desenvolvido.

Aproveitamos para, nas comemorações do $10^{\circ}$ aniversário, convidar pesquisadores de outros grupos de pesquisa no campo das políticas educacionais a apresentarem textos que ilustrassem a trajetória de seus centros de investigação, apontando um tanto os percalços, conquistas e desafios para a pesquisa no campo. Isto parece importante para o campo, pois se trata de um processo de aprendizagem e de constante reinvenção. A socialização dessas experiências pode incentivar a constituição de outros grupos e/ou colaborar de alguma maneira com a busca por soluções para problemas comuns ao campo.

Mas, na abertura desta edição, temos antes de tudo o texto da professora Nora Krawczyk, que nos apresenta uma historicidade da pesquisa no campo das políticas educacionais. O texto organizado pela professora discute as trajetórias históricas de constituição do campo de pesquisa no Brasil, demonstrando os caminhos teóricos perseguidos pelo campo, e apontando um conjunto de desafios para a pesquisa em políticas educacionais, destacadamente o necessário aprofundamento do debate teórico e histórico, a desnaturalização das categorias de análise e a articulação entre as diferentes áreas e abordagens teórico-metodológicas.

Na sequência, temos dois artigos da região sul do Brasil. No primeiro, organizado pela professora Taís Moura Tavares, apresenta-se justamente a constituição do NuPE/UFPR. O artigo objetiva expressar a trajetória diversa e ampliada do núcleo e as suas formas de inserção no movimento de constituição e definição do campo das políticas educacionais. A autora destaca que há, ainda, muito a ser feito no desenvolvimento de pesquisa, mas que o grupo já tem galgado passos significativos em direção à aquisição de competências em diferentes linhas e metodologias de pesquisa do campo. Por fim, o texto destaca alguns dos desafios que o núcleo ainda tem pela frente, em particular no que tange ao necessário adensamento teórico e metodológico.

O outro artigo que nos foi enviado e que expressa a organização de um importante grupo de pesquisa no campo da região sul, é de autoria de um coletivo de autores (Maria Beatriz Luce; Nalú Farenzena; Vera Maria Vidal Peroni; Naira Lisboa Franzoi; Juca Gil), colegas pesquisadores do Núcleo de Estudos de Política e Gestão da Educação da Universidade Federal do Rio Grande do Sul. O núcleo, segundo os autores, tem dado destaque, desde sua criação, há 20 anos, aos diversos âmbitos do ensino, da produção científica, da pesquisa, da extensão universitária, das relações com a comunidade acadêmica nas atividades de pesquisa e da inserção de seus integrantes em ações de caráter político e acadêmico-administrativo. A história do Núcleo da UFRGS é marcada pela presença de muitas pessoas, tanto acadêmicos quanto de fora da academia, com o desenvolvimento de trabalhos, todos listados e discutidos no texto, focados na ideia de contribuir para a democratização da educação e do Estado. 
O Núcleo de Estudos, Pesquisa e Documentação Educação, Sociedade e Cultura - Nedesc, da Universidade Federal de Goiás tem sua trajetória e desafios apresentados no artigo de autoria de João Ferreira de Oliveira e Lúcia Maria de Assis, que traz a contribuição da região centro-oeste para esta reflexão sobre os grupos de pesquisa em políticas educacionais no Brasil. Neste texto, os autores analisam a constituição do Nedesc, observando as dificuldades metodológicas e organizacionais enfrentadas na formação de pesquisadores nos diversos níveis, desde a Iniciação Científica até o Doutorado em Educação, bem como, pontua os desafios às tendências de investigação na área da Educação, sobretudo em história da educação, políticas, organização e gestão, que se constituem nas áreas de atuação do núcleo.

Da região norte do país, vem o texto de autoria de Rosana Gemaque, Dalva Valente Gutierrez, Danielle Cristina de Brito Mendes, que trata da organização e funcionamento do Grupo de Estudo em Gestão e Financiamento da Educação (GEFIN), do Instituto de Ciências da Educação da Universidade Federal do Pará. O grupo, que já tem 14 anos de funcionamento, é focado na investigação e aprofundamento de questões relacionadas à gestão e ao financiamento da educação por meio de um processo coletivo de formação. No texto, as autoras apresentam elementos para o debate sobre essa forma coletiva de formação e produção de conhecimentos. $\mathrm{O}$ artigo ainda destaca aspectos positivos, dificuldades e desafios na manutenção do próprio grupo. Ao final, o texto destaca que mesmo com o aumento de atribuições para o pesquisador decorrente do trabalho coletivo, o processo de formação e produção de conhecimentos vem se consolidando como experiência muito importante.

O último texto voltado a expressar as trajetórias dos grupos de pesquisa em políticas educacionais vem da região sudeste, no qual a professora Theresa Adrião, apresenta o processo de constituição e desenvolvimento do Grupo de Estudos e Pesquisas em Política Educacional - GREPPE, sediado na UNICAMP e que teve início na UNESP-Rio Claro no início da década de 2000. A autora mostra como o grupo surgiu a partir da confluência de fatores de três ordens: de uma necessidade objetiva, de uma perspectiva política e de aprendizados. O artigo evidencia, assim, que a necessidade objetiva de abrigar o esforço coletivo de diversos pesquisadores, até a disposição em desenvolver ações e lutas mesmo políticas na defesa da educação pública de qualidade para todos, foram fatores decisivos na constituição do grupo, que tem desenvolvido amplos e diversos estudos e intervenções no campo da pesquisa em políticas educacionais.

Nesses dez anos do NuPE, a internacionalização sempre foi um desafio para nós. Assim, desde 2011 vimos constituindo esforços para nos aproximar e criar laços de cooperação com pesquisadores de outros países. 0 último artigo desta edição vem justamente da principal ação de internacionalização do núcleo, que é um projeto de cooperação internacional e de pesquisa comparada que desenvolvemos junto ao Instituto de Investigación y Desarrollo Educacional, da Univesidade de Talca, Chile. Neste texto, os colegas pesquisadores Sebastián Donoso-Díaz, Moyra Castro-Paredes, Giselle Davis -Toledo, analisam os principais componentes das visões dominantes da política educacional chilena no período recente (de 1990 até começos de 2010), coincidindo com os governos que se sucederam dentro da coalização política denominada "concertación de Partidos por la Democracia". A revisão dos enfoques da política educacional é relevante para compreender os sucessos ocorridos, como também dá conta de algumas determinantes que incidem nas propostas de políticas hoje em curso, permitindo delinear os desafíos que se avizinham. O texto finaliza apontando que esses vinte anos no Chile se caracterizaram pelas tensões e conflitos entre uma visão de estado social e uma de estado neoliberal.

Esta edição é, portanto, um dos presentes do (e para o) NuPE/UFPR. Que a próxima década do núcleo seja tão rica e diversa e produtiva quanto a primeira. Registro, ao final, um especial agradecimento aos colegas dos demais núcleos de pesquisa que nos enviaram os artigos, dando corpo ao projeto de registrar esta história de pesquisa em políticas educaionais.

Boa leitura a todos! 